\title{
Apoptosis Induced via Gamma Delta T Cell Antigen Receptor "Blocking" Antibodies: A Cautionary Tale
}

Indrani Dutta, Lynne-Marie Postovit and Gabrielle M. Siegers*

Department of Oncology, University of Alberta, Edmonton, AB, Canada

Mechanistic studies contribute greatly to our understanding of $\gamma \delta T$ cell $(\gamma \delta T c)$ biology, aiding development of these cells as immunotherapeutic agents. The antibody blocking assay is an accepted method to determine the receptors involved in $\gamma \delta$ Tc killing of tumor targets. Effectors and/or targets are preincubated with microgram quantities of monoclonal antibodies (mAb), often described by commercial sources to be useful for blocking assays. We and others have used such assays extensively in the past, correlating decreases in cytotoxicity against specific targets with involvement of the blocked receptor(s). However, we wondered whether other mechanisms might be at play beyond cytotoxicity inhibition. Indeed, administration of certain "blocking" mAb to the $\gamma \delta T$ cell antigen receptor $(\gamma \delta \mathrm{TCR})$ induced $\gamma \delta \mathrm{Tc}$ death. Upon further investigation, we discovered

OPEN ACCESS

Edited by:

Loretta Tuosto,

Sapienza Università di Roma, Italy

Reviewed by: Immo Prinz,

Hannover Medical School, Germany

Elena Lo Presti,

University of Palermo, Italy

${ }^{*}$ Correspondence: Gabrielle M. Siegers siegers@ualberta.ca

Specialty section: This article was submitted to T Cell Biology,

a section of the journal

Frontiers in Immunology

Received: 13 April 2017 Accepted: 19 June 2017 Published: 30 June 2017

Citation:

Dutta I, Postovit LM and Siegers GM (2017) Apoptosis Induced via Gamma Delta T Cell Antigen Receptor "Blocking" Antibodies: A Cautionary Tale.

Front. Immunol. 8:776. doi: 10.3389/fimmu.2017.00776 that $\gamma \delta \mathrm{Tc}$ underwent apoptosis triggered by incubation with mAb to the $\gamma \delta \mathrm{TCR}$. This effect was specific, as no apoptosis was observed when $\alpha \beta$ T cells ( $\alpha \beta T$ T) were incubated with these mAb. Apoptosis was further potentiated by the presence of interleukin (IL)-2, often included in cytotoxicity assays; however, exogenous interleukin-2 (IL-2) did not contribute significantly to $\gamma \delta$ Tc cytotoxicity against breast cancer cell lines. Here, we have investigated the usefulness of four mAb for use in blocking assays by assessing blocking properties in conjunction with their propensity to induce apoptosis in cultured primary human $\gamma \delta \mathrm{TC}$. We found that the 5A6.E9 clone was usually a better alternative to the commonly used B1 (or B1.1) and 11F2 clones; however, some variability in susceptibility to apoptosis induction was observed among donor cultures. Thus, viability assessment of primary effector cells treated with mAb alone should be undertaken in parallel with cytotoxicity assays employing blocking antibodies, to account for cytotoxicity reduction caused by effector cell death. Previous findings should be reassessed in this light.

Keywords: gamma delta T cells, blocking antibodies, cytotoxicity, mechanism, apoptosis

\section{INTRODUCTION}

$\gamma \delta \mathrm{T}$ cells $(\gamma \delta \mathrm{Tc})$ are potent tumor cell killers, thought to identify their targets via cell surface receptors such as the $\gamma \delta \mathrm{Tc}$ antigen receptor $(\gamma \delta \mathrm{TCR})$ and natural killer receptors, like NKG2D (1). $\gamma \delta \mathrm{Tc}$ are particularly attractive for cancer immunotherapy, as they recognize antigens directly on transformed cells and kill quickly (with no need for priming or clonal expansion); among other

Abbreviations: $\alpha \beta \mathrm{Tc}$, alpha beta T cells; AICD, activation-induced cell death; AnnV, annexin V; CalAM, calcein AM; FB, FACS buffer; FBS, fetal bovine serum; IL, interleukin; mAb, monoclonal antibodies; $\gamma \delta \mathrm{Tc}$, gamma delta T cells; $\gamma \delta \mathrm{TCR}$, gamma delta T cell antigen receptor; PBMCs, peripheral blood mononuclear cells; SSC, side scatter; ZA, Zombie Aqua. 
advantageous features, expertly reviewed in Ref. (2), $\gamma \delta$ Tc do not cause graft-versus-host disease (2). In preclinical studies, we and others have shown that $\gamma \delta$ Tc kill many types of hematological and solid malignancies $(2,3)$. Furthermore, in vivo expansion of $\gamma \delta \mathrm{Tc}$ has yielded promising results in Phase I clinical trials treating metastatic prostate cancer (4), renal cell carcinoma (5), advanced breast cancer (6), and low grade non-Hodgkin lymphoma and multiple myeloma (7) reviewed together with adoptive $\gamma \delta \mathrm{Tc}$ immunotherapy trials in Ref. (8). We aim to learn more about $\gamma \delta \mathrm{Tc}$ in the context of breast cancer, to further development of $\gamma \delta \mathrm{Tc}$ immunotherapy for this disease.

Determining the mechanism(s) of action employed by $\gamma \delta \mathrm{Tc}$ against tumor cells is crucial for their further development as immunotherapy for cancer. The antibody blocking assay is an accepted method to determine the receptors involved in $\gamma \delta \mathrm{Tc}$ cytotoxicity against tumor targets (9-23). Effectors and/or targets are preincubated with microgram quantities of "blocking" monoclonal antibodies $(\mathrm{mAb})$ and then co-incubated for the cytotoxicity assay, whereby decreased cytotoxicity against targets is attributed to involvement of the blocked receptor(s). A wide range of pan anti- $\gamma \delta$ TCR antibody clones have been used in these assays, including 11F2 (11, 17), B1 (14), B1.1 (9, 10, 18, 22, 23), STCS1 $(12,21)$, and Immu510 $(9,10)$, as well as a mAb specific to the $\operatorname{V\gamma } 9$ TCR $(1,3,15,16)$. Please note that clones B1 and B1.1 anti- $\gamma \delta$ TCR mAb clones are considered to be one and the same, simply sold by different companies (Biolegend's Product Data Sheet for B1, Application Notes). Unfortunately, tracing the origins of commercially sold antibodies whose generation has not been documented in the literature is challenging, if not impossible.

While bona fide blocking of the $\gamma \delta T C R$ may indeed hinder $\gamma \delta \mathrm{Tc}$ cytotoxicity, other mechanisms, such as effector cell death, may contribute to decreases in cytotoxicity, thus leading to false interpretation of assay results. Indeed, an early study using $\gamma \delta \mathrm{Tc}$ clones showed that apoptosis can be induced by TCR/CD3 signaling in as little as $4 \mathrm{~h}$ incubation with soluble or immobilized 7A5 (recognizing an epitope on the V $\gamma 9$ TCR chain) or BMA030 (anti-CD3) and that this process was interleukin (IL)-2 dependent (24). To the best of our knowledge, no further studies have been undertaken to characterize other anti- $\gamma \delta \mathrm{TCR} \mathrm{mAb}$ in this way. We decided to test four pan anti- $\gamma \delta$ TCR mAb clones, three of which have been used previously in such blocking assays: B1 (14), B1.1 $(9,10,18,22,23)$, and 11F2 $(11,17)$ plus 5A6.E9 that, to the best of our knowledge, has only been reported once in the context of $\gamma \delta T C R$ blocking in the literature (21). We set out to determine the best clone and conditions to use to further our understanding of mechanisms of $\gamma \delta$ Tc cytotoxicity against tumor targets, through the correct interpretation of assay results.

\section{MATERIALS AND METHODS}

\section{Ethics Statement}

This study was carried out in accordance with the recommendations of the Research Ethics Guidelines, Health Research Ethics Board of Alberta-Cancer Committee with written informed consent from all subjects. All subjects gave written informed consent in accordance with the Declaration of Helsinki. The protocol was approved by the Health Research Ethics Board of Alberta-Cancer Committee.

\section{Primary $\gamma \delta \boldsymbol{T}$ Cells}

Primary human $\gamma \delta \mathrm{Tc}$ and $\alpha \beta \mathrm{Tc}$ cultures were established and maintained as described (9). Briefly, peripheral blood mononuclear cells were isolated from healthy donor blood using density gradient separation (Lymphoprep, Stem Cell Technologies, Vancouver, BC, Canada) and cultured at $1 \times 10^{6}$ cells $/ \mathrm{ml}$ in RPMI complete medium containing $1 \mu \mathrm{g} / \mathrm{ml}$ concanavalin A (Sigma-Aldrich, Oakville, ON, Canada), 10\% fetal bovine serum (FBS), 1× MEM NEAA, 10 mM HEPES, $1 \mathrm{mM}$ sodium pyruvate (all Invitrogen, Burlington, ON, Canada) plus $10 \mathrm{ng} / \mathrm{ml}$ recombinant human IL-2 and IL-4 (Miltenyi Biotec, Auburn, CA, USA). Every 3-4 days, cells were counted and densities adjusted to $1 \times 10^{6}$ cells $/ \mathrm{ml}$ by addition of fresh medium and cytokines. Cells were maintained in a humidified atmosphere at $37^{\circ} \mathrm{C}$ with $5 \% \mathrm{CO}_{2}$. After 1 week, $\alpha \beta \mathrm{Tc}$ were depleted after labeling with anti-TCR $\alpha \beta$ PE antibodies (BioLegend, San Diego, CA, USA) and anti-PE microbeads (Miltenyi Biotec), filtering through a $50 \mu \mathrm{m}$ Cell Trics filter (Partec, Görlitz, Germany) and running through an LD depletion column (Miltenyi Biotec). The flow-through contained $\gamma \delta \mathrm{Tc}$, which were further cultured in RPMI complete medium plus cytokines (as above) at $37^{\circ} \mathrm{C}$ with $5 \% \mathrm{CO}_{2}$. For some experiments, the positively selected $\alpha \beta \mathrm{Tc}$ were also recovered and maintained. For cytotoxicity experiments, $\gamma \delta$ Tc cultures were used at the end of the culture period (day 19-21), as they were most differentiated and therefore most cytotoxic at this time. Blocking assays were also typically done at this time, to mimic conditions used for cytotoxicity assays. Some experiments were done at earlier time points (days 14-16), and susceptibility to $\mathrm{mAb}$-induced cell death did not appear to be significantly different, although this was not tested directly. Donor cultures are identified as follows: donor number-culture number; thus, 3-2 = the second culture derived from donor 3 .

\section{Breast Cancer Cell Lines}

Breast cancer cell lines MCF-7, T47D, and MDA-MB-231 were obtained from the American Type Culture Collection (ATCC, Manassas, VA, USA) and maintained as per ATCC guidelines.

\section{Calcein AM (CalAM) Labeling of Target Cells}

Target cells were labeled with $5 \mu \mathrm{M}$ CalAM as per the manufacturer's instructions (Invitrogen/Thermo Fisher Scientific, Waltham, MA, USA). Cells were diluted to a density of 30,000 cells/100 $\mu \mathrm{l}$ medium for use in cytotoxicity assays.

\section{"Blocking" Antibodies}

The following antihuman anti- $\gamma \delta \mathrm{TCR} \mathrm{mAb}$ clones were used: B1 (BioLegend, San Diego, CA, USA), B1.1 (25) (eBioscience, San Diego, CA, USA), 5A6.E9 (26) (Thermo Fisher Scientific, Waltham, MA, USA), and 11F2 (27) (Becton Dickinson, Mississauga, ON, Canada); mouse IgG (Sigma-Aldrich, Oakville, ON, Canada) was used as a control. The anti-NKG2D antibody 
was purchased from BioLegend (Clone 1D11). For immobilization, $\mathrm{mAb}$ were diluted at $1 \mu \mathrm{g} / \mathrm{ml}$ in PBS, then plated at $100 \mu \mathrm{l} /$ well and incubated overnight at $4^{\circ} \mathrm{C}$. Prior to blocking assays, the plates were washed twice with PBS.

\section{Blocking/Cytotoxicity Assay}

$\gamma \delta \mathrm{Tc}$ cells were resuspended at $6 \times 10^{6}$ cells $/ \mathrm{ml}$ in complete medium (RPMI 1640 with 10\% FBS, heat-inactivated, $1 \times$ MEM NEAA, $10 \mathrm{mM}$ HEPES, $1 \mathrm{mM}$ sodium pyruvate, $50 \mathrm{U} / \mathrm{ml}$ penicillin-streptomycin, and $2 \mathrm{mM} \mathrm{L}$-glutamine-all from Invitrogen) plus $20 \mathrm{ng} / \mathrm{ml}$ recombinant human IL-2 (Miltenyi Biotec, Auburn, CA, USA) where indicated. For Fc blocking experiments, $5 \mu \mathrm{l}$ Human TruStain FcX (BioLegend, San Diego, CA, USA) were added per 600,000 cells in $100 \mu \mathrm{l}$ and incubated for $10 \mathrm{~min}$ at room temperature prior to the addition of $\mathrm{mAb} .6 \mu \mathrm{g} \mathrm{mAb}$ was added to $600 \mu \mathrm{l}$ cell suspension/test in Eppendorf tubes, then $100 \mu \mathrm{l} /$ well plated in a 96-well round-bottomed plate. After incubation at $37^{\circ} \mathrm{C}$ for $30 \mathrm{~min}, 100 \mu \mathrm{l}$ complete medium only (blocking assay only), or CalAM-labeled targets were added (cytotoxicity assay). After further incubation at $37^{\circ} \mathrm{C}$ for $4 \mathrm{~h}$, two wells/condition of resuspended cells were pooled and stained for flow cytometry (blocking assay only). Experimental controls were untreated and IgG-treated cells. For cytotoxicity assays, plates were centrifuged and supernatants transferred to fresh 96-well plates (Falcon, U bottom, low evaporation) for CalAM fluorescence detection on a fluorimeter (FLUOstar Omega, BMG labtech). Controls were CalAM-labeled target cells incubated alone $($ spon $=$ spontaneous release) and $0.05 \%$ Triton-X 100 (Thermo Fisher Scientific)treated cells $(\max =$ maximum release). Percent lysis was calculated: $[($ test - spon $) /(\max -$ spon $)] \times 100 \%$.

\section{Flow Cytometry \\ $\gamma \delta$ T Cell Subset Identification}

Cultured $\gamma \delta \mathrm{Tc}$ were stained first with $5 \mathrm{ng} / \mu \mathrm{l}$ Zombie Aqua (ZA) fixable viability dye (BioLegend) and then with anti-TCR V $\delta 1$ FITC (Thermo Fisher Scientific, clone TS8.2, 1:10), anti-TCR V82 PerCP (BioLegend, clone B6, 1:50), and anti-TCR $\gamma \delta$ PE (BioLegend, clone B1, 1:25). After staining and washing, cells were fixed in FACS buffer plus $2 \%$ paraformaldehyde, stored at $4^{\circ} \mathrm{C}$ and analyzed by flow cytometry within 1 week. Subset and purity data for all cultures are shown in Table S1 in Supplementary Material.

\section{Detection of Apoptosis (28)}

Cultured $\gamma \delta \mathrm{Tc}$ were first stained with $5 \mathrm{ng} / \mu \mathrm{l} \mathrm{ZA}$ fixable viability dye (BioLegend) for 15-20 min, washed with $1 \times$ annexin $\mathrm{V}$ (AnnV) binding buffer (BioLegend), and then stained on ice for $15 \mathrm{~min}$ in the dark with AnnV FITC (BioLegend, 1:20). Cells were washed and resuspended in $200 \mu \mathrm{l} \mathrm{AnnV}$ binding buffer plus $2 \%$ paraformaldehyde and stored at $4^{\circ} \mathrm{C}$ until analyzed. Flow cytometry was performed on a FACS Canto II (Becton Dickinson, Mississauga, ON, Canada), calibrated with Cytometer Set-up and Tracking beads (Becton Dickinson). Gating in forward and side scatter was done only to exclude debris; quadrant gates were set using single-stain controls. Analysis was performed using FlowJo@ software (Tree Star, Ashland, OR, USA, Version 10.0.8).

\section{Stimulation Experiments}

$\gamma \delta \mathrm{Tc}$ were incubated for $4 \mathrm{~h}$ at $37^{\circ} \mathrm{C}, 5 \% \mathrm{CO}_{2}$ in serum-free and cytokine-free medium; they were then stimulated with $1 \mu \mathrm{g} \mathrm{mAb}$ for $1 \mathrm{~min}$ at $37^{\circ} \mathrm{C}$. Anti-CD3 (UCHT1, BioLegend) stimulated cells were a positive control. Lysates were run on $12 \%$ SDS PAGE and Western blotting performed using a 1:400 dilution of the PathScan ${ }^{\circledR}$ Multiplex Western Cocktail I (Cell Signaling Technology, Danvers, MA, USA) to detect phosphorylated signaling proteins.

\section{Statistics}

Paired 1-tailed Student's $t$-tests were performed (Figures 2E-G only) using Microsoft Excel version 15.3 (Microsoft, Redmond, WA, USA). ANOVA analysis followed by Bonferroni's pairwise multiple comparison post hoc tests were performed using Prism 7.0 for Mac OSX (GraphPad Software, San Diego, CA, USA). Differences were considered significant when $P<0.05$; degrees of significance are indicated by letters or asterisks as defined in the figure legends.

\section{RESULTS}

\section{An Alternate Explanation for Reduced Cytotoxicity upon Treatment with "Blocking" Antibody}

Incubation of $\gamma \delta \mathrm{Tc}$ with anti-human pan $\gamma \delta \mathrm{TCR}$ mAb clones B1, $5 \mathrm{~A} 6 . \mathrm{E} 9$, and $11 \mathrm{~F} 2$ reduces the cytotoxicity of human $\gamma \delta \mathrm{Tc}$ against T47D breast cancer cells by 1.6 - to 2.8 -fold/14-25\% compared to IgG controls (Figure 1A). Yet if all three $\mathrm{mAb}$ perform an equivalent blocking function, we would expect the same decrease in lysis to occur in all cases. On the contrary, there was less reduction in average cytotoxicity with 5A6.E9 (12\%) compared to 11F2 (22\%) and B1 (25\%) clones. One-way ANOVA followed by Bonferroni's multiple comparisons test revealed significant differences in cytotoxicity for B1- and 11F2-blocked $\gamma \delta \mathrm{Tc}(P=0.0023$ and $P=0.0051$, respectively), whereas the decrease in cytotoxicity with 5A6.E9 $\mathrm{mAb}$ was not significant $(P=0.1065)$ compared to IgG. This lead us to further investigate whether other mechanisms may be at play. Untreated controls were included in parallel to IgG and $\mathrm{mAb}$ treatments in most experiments, to verify similarity to IgG controls. However, statistical analyses reported herein focus on $\mathrm{mAb}$ versus IgG treatments; for simplicity, statistical analyses of $\mathrm{mAb}$ versus untreated control samples are not shown.

When we incubated $\gamma \delta \mathrm{Tc}$ alone with anti- $\gamma \delta \mathrm{TCR}(\mathrm{B} 1)$, antiNKG2D, or IgG control antibodies for $4.5 \mathrm{~h}$, in the absence of targets, uptake of ZA viability dye indicated increased cell death in B1- but not in anti-NKG2D-treated cells (Figure 1B, gating controls in Figure S1A in Supplementary Material). Thus, the decrease in cytotoxicity observed after $\gamma \delta T C R$ "blocking" appears to be at least partially due to the untimely death of a significant proportion of effector $\gamma \delta \mathrm{Tc}$. Importantly, this did not occur when anti-NKG2D was used, suggesting that prior interpretations implicating NKG2D in cytotoxicity were not compromised by the induction of effector cell death described here.

To further define this cell death, we extended our experiments to include AnnV staining for the detection of apoptotic 
A

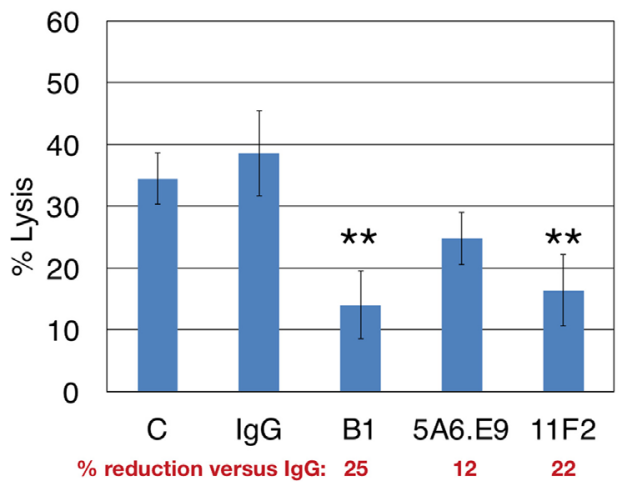

C

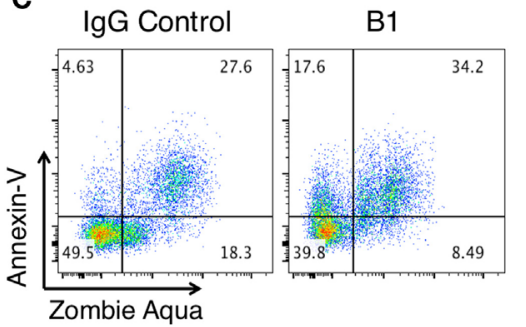

B1.1

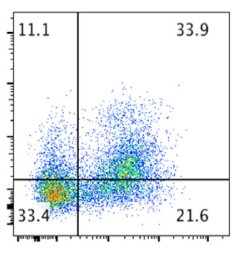

E

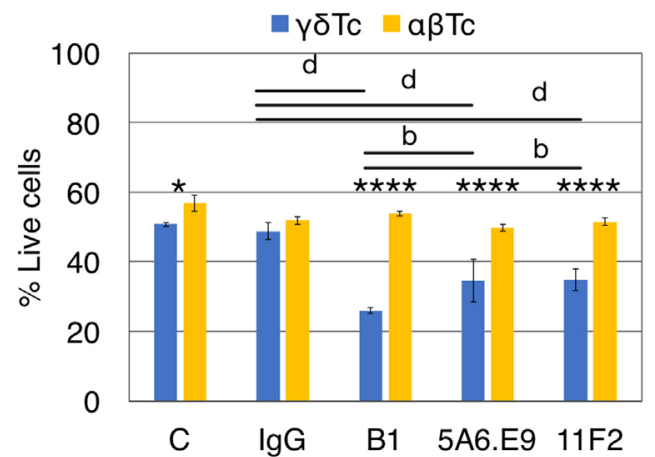

B
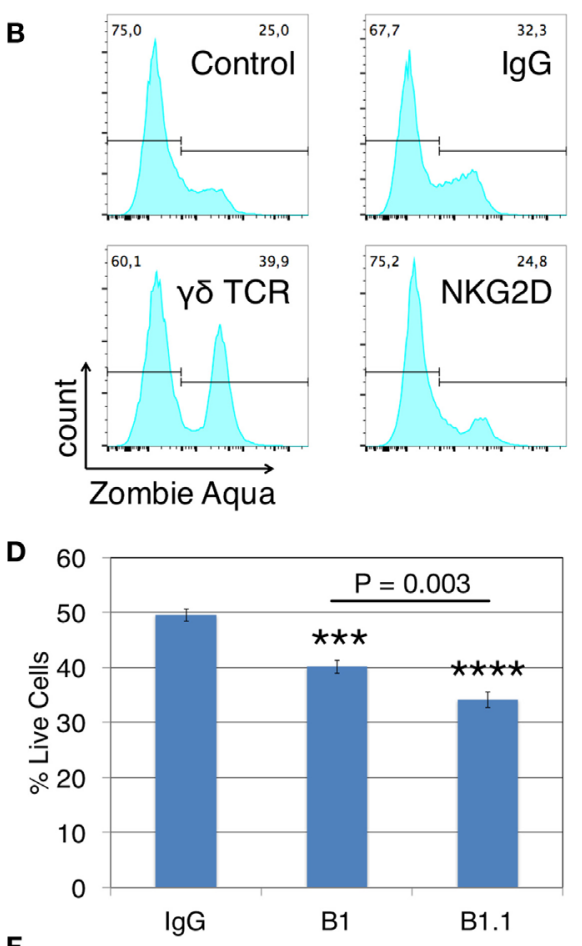

$\mathbf{F}$

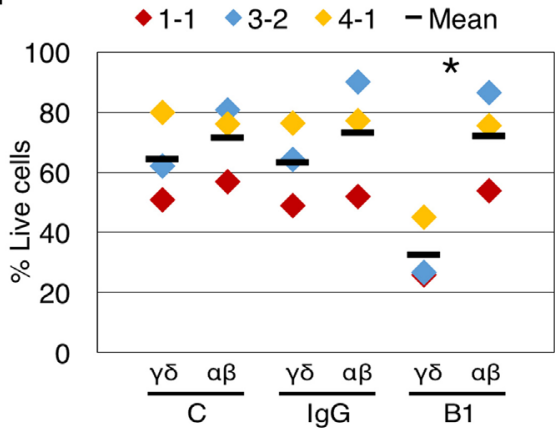

FIGURE $1 \mid$ Anti- $\gamma \delta$ TCR antibodies reduce lysis of breast cancer cells concomitant with $\gamma \delta \mathrm{T}$ cell death. (A) Donor 1 day 21 primary human $\gamma \delta \mathrm{T}$ cells were preincubated for $30 \mathrm{~min}$ with $(1 \mu \mathrm{g} /$ well) or without antibodies $(\mathrm{C}=$ control), then incubated with calcein AM-labeled T47D targets in triplicate at a 20:1 effector:target (E:T) ratio for $4 \mathrm{~h}$. A significant reduction in \% lysis was observed in the presence of anti- $\gamma \delta T C R$ antibodies. Percent reduction compared to lgG (red font) was calculated: $100-$ (\% lysis or live cells treated with antibody/lgG $\times$ 100). (B) Representative example showing that treatment of 600,000 Donor 2 day $14 \gamma \delta T$ cells for $4.5 \mathrm{~h}$ with $1 \mu \mathrm{g}$ antibody alone induces cell death as evidenced by Zombie Aqua Viability dye uptake. (C) Representative example indicates induction of apoptosis in Donor 3 day $21 \gamma \delta$ T cells via antibody treatment as in panel (B). (D) Summary of results from experiment shown in panel (C). (E) Treatment of Donor 1 $\alpha \beta$ T cells with anti-TCR $\gamma \delta$ antibodies does not cause cell death. (F) Compiled results for three independent experiments, focusing on B1 versus lgG. Error bars indicate SD $(n=3)$; significant differences compared to lgG controls (A,D) or between $\alpha \beta$ and $\gamma \delta T$ cells $\mathbf{( E , F ) ~ w e r e ~ d e t e r m i n e d ~ b y ~ o n e - w a y ~ ( A , D ) ~ o r ~ t w o - w a y ~ ( E , F ) ~}$ ANOVA followed by Bonferroni's multiple comparisons test $\left({ }^{\star} P<0.05,{ }^{\star \star} P<0.01,{ }^{\star \star \star} P<0.001,{ }^{* \star \star *} P<0.0001 ;{ }^{b} P<0.01,{ }^{d} P<0.0001\right)$.

cells via flow cytometry (28). We categorized cell death into early apoptotic $(\mathrm{AnnV}+/ \mathrm{ZA}-)$, late apoptotic $(\mathrm{AnnV}+/ \mathrm{ZA}+)$, and necrotic $(\mathrm{AnnV}-/ \mathrm{ZA}+)$ fractions. Treatment of $\gamma \delta \mathrm{Tc}$ with $\mathrm{B} 1$ and B1.1 anti- $\gamma \delta \mathrm{TCR}$ blocking $\mathrm{mAb}$ resulted in increased apoptotic cell death compared to IgG controls, in both early (17.6 and 11.1 versus $4.6 \%)$ and late apoptotic compartments (34.2 and 33.9 versus $27.6 \%$ ) in a representative example (Figure 1C; gating controls in Figure S1B in Supplementary Material); combined results for technical replicates from this experiment are also shown $(n=3$, Figure 1D). One-way ANOVA followed by Bonferroni's pairwise multiple comparison post hoc analysis revealed significant reductions in cell viability after incubation with B1 $(P=0.0003)$ and B1.1 $(P<0.0001) \mathrm{mAb}$ compared to IgG. Surprisingly, a significant $\gamma \delta$ Tc viability difference was also found comparing $\mathrm{B} 1$ and $\mathrm{B} 1.1(P=0.0003)$, considered to be the same $\mathrm{mAb}$, simply sold by different companies. The BioLegend product data sheet for $\mathrm{B} 1$ states "Clone $\mathrm{B} 1$ is also known as clone B1.1"; however, the nomenclature would suggest that B1.1 is a subclone of B1. Unfortunately, we were unable to learn anything about the generation of these clones, which is not reported in the literature. Since the effect (viability loss) was always similar in experiments carried out with both antibody clones (data not 


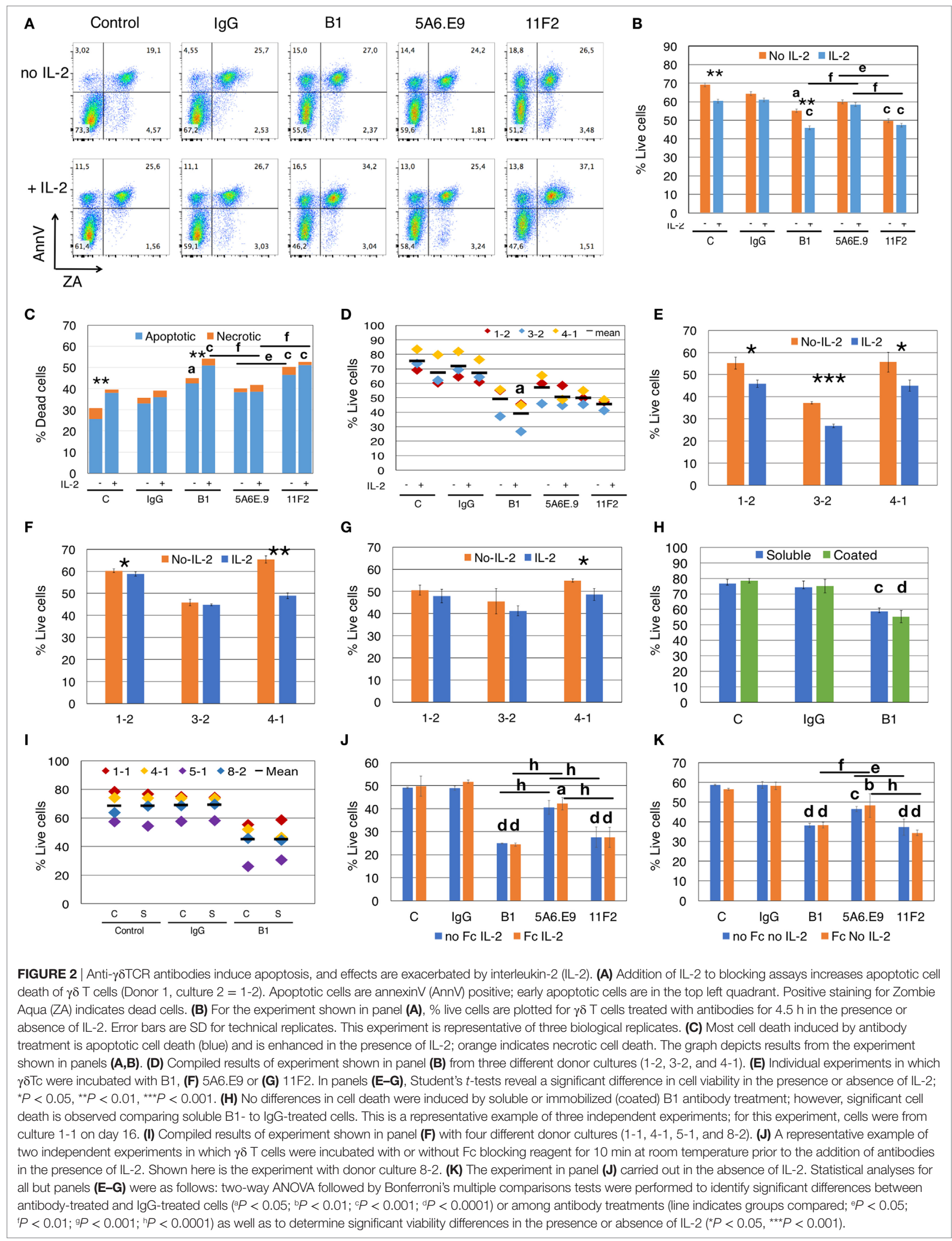


shown), yet B1.1 had a more significantly negative effect on $\gamma \delta \mathrm{Tc}$, we used B1 for all experiments moving forward.

Induction of cell death via anti- $\gamma \delta$ TCR incubation was specific to $\gamma \delta \mathrm{Tc}$, since the viability of $\alpha \beta \mathrm{Tc}$ expanded in parallel from the same donor was not compromised by incubation with B1, 5A6.E9, or 11F2 (Figure 1E). $\alpha \beta$ Tc viability remained unchanged, while once again, the strongly significant reduction in $\gamma \delta \mathrm{Tc}$ viability after treatment with B1, 5A6.E9, and 11F2 compared to IgG was confirmed $(P<0.0001)$. Notably, there was also a significant difference in viability between $\mathrm{B} 1$ and 5A6.E9 $(P=0.0034)$ as well as between B1 and 11F2 $(P=0.0040)$, demonstrating that the detrimental effect of $\mathrm{B} 1$ is greater than that of the other two clones. While there was a significant difference in $\gamma \delta$ Tc versus $\alpha \beta$ Tc viability in the control samples, which is understandable, as these are two different cultures (albeit derived from the same donor), there was no difference in $\alpha \beta$ Tc viability among antibody treatments or controls. Three independent experiments with three different donor cultures testing B1 compared to IgG and control are shown and the significant drop in $\gamma \delta \mathrm{Tc}$ viability after incubation with B1 was confirmed (Figure 1F, $P=0.02$ ).

To determine whether stimulation with anti- $\gamma \delta \mathrm{TCR} \mathrm{mAb}$ clones differentially activates $\gamma \delta \mathrm{Tc}$, we stimulated effector $\gamma \delta \mathrm{Tc}$ for $1 \mathrm{~min}$ with anti- $\gamma \delta \mathrm{TCR} \mathrm{mAb}$ and used anti-CD3 stimulation with the UCHT1 clone as a positive control for activation. While clones B1 and B1.1 did not cause phosphorylation of signaling proteins AKT, ERK1/2, or S6 above that of the unstimulated control, clones 11F2 and 5A6.E9 elicited a phosphorylation pattern similar to that obtained with anti-CD3 stimulation (UCHT1) suggesting active signaling (Figure S2 in Supplementary Material). Rab11 served as an internal loading control. Clones B1 and B1.1 behaved as blocking antibodies should, by not inducing activation; however, a lack of survival signaling through phosphoAKT cannot account for the cell death observed in B1-treated $\gamma \delta \mathrm{Tc}$, since the untreated control cells in our blocking experiments did not die to the same extent, although their activation patterns are quite similar (Figure S2 in Supplementary Material, compare lanes 1-3).

\section{IL-2 Enhances Apoptotic Cell Death Induced by Anti- $\gamma \delta$ TCR Antibody Treatment}

We tested whether exogenous IL-2 impacts the viability of $\gamma \delta \mathrm{Tc}$ in the presence of $\mathrm{B} 1,5 \mathrm{~A} 6 \mathrm{E} 9$, or $11 \mathrm{~F} 2 \mathrm{mAb}$ in a $4.5 \mathrm{~h}$ assay. Representative dot plots show that incubation with $\mathrm{mAb}$ resulted in an increase in both early apoptotic $(\mathrm{AnnV}+/ \mathrm{ZA}-)$ and late apoptotic $(\mathrm{AnnV}+/ \mathrm{ZA}+) \gamma \delta \mathrm{Tc}$, even in the absence of exogenous IL-2 (Figure 2A; gating shown in Figure S1C in Supplementary Material). Two-way ANOVA followed by Bonferroni's multiple comparison post hoc statistical analysis revealed significant loss of $\gamma \delta$ Tc viability due to IL-2 only in control $(P<0.0074)$ and B1-treated groups $(P=0.0042$, Figure $2 B)$. In contrast, no IL-2induced differences in viability were observed in cell populations treated with IgG, 5A6.E9, or 11F2 mAb; however, both B1 and $11 \mathrm{~F} 2 \mathrm{mAb}$ decreased $\gamma \delta \mathrm{Tc}$ viability significantly compared to IgG controls. Notably, 5A6.E9 treatment did not elicit significant loss of cell viability compared to IgG in this experiment. In the presence of IL-2, 5A6.E9-treated cells were more viable than those incubated with $\mathrm{B} 1(P=0.0016)$ or $11 \mathrm{~F} 2(P=0.0067)$; the decrease in $\gamma \delta \mathrm{Tc}$ viability after incubation with $11 \mathrm{~F} 2$ compared to $5 \mathrm{~A} 6 . \mathrm{E} 9$ in the absence of IL-2 was also deemed significant $(P=0.0163)$. Importantly, the difference in average $\gamma \delta \mathrm{Tc}$ viability between IgG- and B1-treated cells could account for a large proportion (if not all) of the decrease in cytotoxicity associated with the use of this $\mathrm{mAb}$ in blocking experiments. The cell death associated with $\mathrm{mAb}$ incubation was mostly apoptotic cell death (Figure 2C), with significant increases in IL-2-dependent cell death observed in control and B1-treated $\gamma \delta T c$. Statistical analysis performed on cell death data shown in Figure 2C revealed the same results as in the reciprocal live cell data in Figure 2B.

We compiled the results for three independent experiments and statistical analysis thereof confirmed significant loss of cell viability $(P=0.0308)$ in $\mathrm{B} 1$ - but not in $11 \mathrm{~F} 2$ - or 5 A6.E9-treated $\gamma \delta \mathrm{Tc}$ compared to IgG in the presence of IL-2 (Figure 2D). To further demonstrate this effect, we show the impact of IL-2 on B1-treated cells from all three experiments (Figure 2E); a synergy was observed between B1 and IL-2 that resulted in significant loss of cell viability compared to B1 treatment in the absence of IL-2. This loss was evident in all three cultures but was most pronounced in the experiment performed with Donor culture 3-2 $(P=0.0006)$. Looking more closely at 5A6.E9 treatments of these three cultures (Figure 2F) revealed a small but significant difference with IL-2 in culture $1-2(60.3 \pm 1.0$ versus $58.8 \pm 0.8 \%$ live cells, without or with IL-2, respectively, $P=0.039$ ), and sensitivity of $4-1$ to IL-2 combined with this clone $(P=0.0048)$. Culture $4-1$ viability was also decreased significantly with combined 11F2 and IL-2 treatment (Figure 2G, $P=0.029$ ). The full experiment done with culture 4-1 is shown in Figure S3B in Supplementary Material. No significant difference in $\gamma \delta$ Tc viability was observed among the three mAb-treated groups in the presence of IL-2 (Figure S3B in Supplementary Material, $P>0.9999)$. In the absence of IL-2, 5A6. E9 elicited the least degree of $\gamma \delta$ Tc cell death and was significantly better than both $\mathrm{B} 1(P=0.0026)$ and 11F2 $(P=0011)$, which were equally detrimental (Figure S3B in Supplementary Material). Donor culture 4-1 was 78.8\% V $22+$ (Figure S3A and Table S1 in Supplementary Material), whereas 1-2 with $14.9 \%$ and 3-2 with $50.8 \%$ V $\delta 2+$ (Table S1 in Supplementary Material) exhibited little to no difference in viability upon incubation with 5A6.E9 or 11F2, with or without IL-2 (Figures 2F,G).

Western blot analysis of cleaved Caspase 3 in total cell lysates did not reveal clear differences among IL-2-treated and untreated cells or mAb treatments over $4.5 \mathrm{~h}$; however, this is a less sensitive method than flow cytometry, thus it was not surprising that we were unable to detect $\sim 10 \%$ differences (data not shown).

We found no differences in $\gamma \delta \mathrm{Tc}$ viability when comparing the use of soluble and immobilized $\mathrm{mAb}$, all in the absence of IL-2; however, B1 treatment resulted in a significant loss of viability compared to IgG-treated $\gamma \delta \mathrm{Tc}$ in both cases in the representative example shown (soluble, $P<0.0005$; coated, $P<0.0001$; Figure 2H). When we included 5A6.E9 and 11F2 in this experiment, again no differences in viability were observed using soluble or immobilized $\mathrm{mAb}$, but significant viability losses compared to IgG were noted (Figure S4 in Supplementary Material). When we compiled results for control, IgG and B1 
treatments from four independent experiments, no significant differences were identified (Figure 2I). This is likely due to interdonor variation, suggesting that variability in cell viability among donors is greater than that observed after treatment with soluble or immobilized $\mathrm{mAb}$.

We tested whether the Fc receptor might be involved in apoptosis induced by $\mathrm{mAb}$ treatment, but found that there were no differences in viabilities of $\gamma \delta \mathrm{Tc}$ that were or were not pretreated with an Fc blocking reagent prior to $\mathrm{mAb}$ incubation (Figures 2J,K). This was true whether IL-2 was present (Figure 2J) or not (Figure $2 \mathbf{K}$ ). Significant decreases in viability were noted for mAb-treated cells (Figures 2J,K), confirming previous results (Figures 2A-I).

To understand the kinetics of apoptosis, we performed a time course experiment that revealed a highly significant decrease in live cells after $3.5 \mathrm{~h}$ of stimulation with B1 that extended to $4.5 \mathrm{~h}$ $(P<0.0001$, Figure S5A in Supplementary Material); of note, there was a significant difference in viability, compared to IgG-treated cells, at the 30 -min time point $(P=0.043)$, but this was no longer evident at 1.5 and $2.5 \mathrm{~h}$ post $\mathrm{mAb}$ treatment. A graph showing the percentage of dead cells over time is also shown (Figure S5B in Supplementary Material). Since cytotoxicity experiments are usually conducted over a minimum of $4 \mathrm{~h}$, this loss of effector viability should be taken into account.

\section{IL-2 Is Not Required for Assessment of $\gamma \delta$ Tc Cytotoxicity against Breast Tumor Targets}

Since the presence of IL-2 during blocking mAb treatment caused unwanted $\gamma \delta \mathrm{Tc}$ death, we investigated whether IL-2 is necessary for assessment of $\gamma \delta$ Tc cytotoxicity against breast tumor targets. In the representative example shown, IL-2 did not significantly enhance $\gamma \delta \mathrm{Tc}$ cytotoxicity against T47D at any effector:target ratio tested (Figure 3A). This was also true for the individual and compiled results of four independent experiments testing $\gamma \delta \mathrm{Tc}$ cytotoxicity against T47D (Figure 3B). We further confirmed these results in cytotoxicity assays against MCF-7 (Figures 3C,D) and MDA-MB-231 (Figures 3E,F) targets. In each case at all ratios tested, there was no significant difference in cytotoxicity of $\gamma \delta \mathrm{Tc}$ against breast tumor targets in the presence or absence of IL-2 (Figure 3).

\section{A Decrease in Lysis of Targets Can Be Partially Explained by Effector Cell Death upon Stimulation with Anti- $\gamma \delta$ TCR Antibodies and Thus Should Be Controlled for in $\gamma \delta$ TCR Blocking Experiments}

Taking all of our previous results into account, we designed parallel blocking-only and blocking plus cytotoxicity assays, in the absence of IL-2, to assess the involvement of $\gamma \delta$ TCR in killing T47D breast tumor targets, while considering anti- $\gamma \delta T C R ~ m A b-$ induced effector cell death. Lysis of T47D targets was reduced dramatically upon treatment of $\gamma \delta \mathrm{Tc}$ with anti- $\gamma \delta \mathrm{TCR} \mathrm{mAb}$; however, incubation with 5A6.E9 did not reduce lysis to quite the same extent, as significant differences in cytotoxicity observed after treatment with $\mathrm{B} 1(P=0.0072)$ and $11 \mathrm{~F} 2(P=0.0128)$ versus 5A6.E9 were evident (Figure 4A). In line with these data, 5A6. E9 also induced significantly less cell death in these donor $\gamma \delta \mathrm{Tc}$ compared to B1, as did 11F2 (Figure 4B, both $P<0.0001$ versus $\mathrm{B} 1$ ). Looking at the percentage of reduction in lysis or live cells compared to IgG, it is evident that at least half of the decrease in percent lysis attributed to $\gamma \delta \mathrm{TCR}$ blocking by B1 is due to $\gamma \delta \mathrm{Tc}$ death, as opposed to blocking interactions between effectors and targets. In this experiment, 5A6.E9 and 11F2 appear to be the better clones for blocking, as $\gamma \delta \mathrm{Tc}$ viability was only reduced by 14 and $23 \%$, respectively, compared to IgG, while they still caused 63 and 87\% reductions in lysis of T47D (Figures 4A,B). A compilation of data from three independent experiments confirmed a decrease in percent lysis of T47D upon treatment with all three anti- $\gamma \delta \mathrm{TCR} \mathrm{mAb}$ clones; however, there was considerable variability in observed cytotoxicity of these different donor cultures against T47D breast cancer targets, rendering differences among treatment groups insignificant (Figure 4C). In contrast, significant reductions in $\gamma \delta$ Tc viability remained evident, despite inter-donor variation, after treatment with $\mathrm{B} 1$ and $11 \mathrm{~F} 2$, but not 5A6.E9 $\mathrm{mAb}$ (Figure 4D). These data confirm results shown in Figures 2A-D.

\section{DISCUSSION}

A reduction of $\gamma \delta \mathrm{Tc}$ cytotoxicity against tumor targets following incubation with pan $\gamma \delta$ TCR blocking $\mathrm{mAb}$ has been attributed to $\gamma \delta$ TCR involvement in killing $(9,11-14,17,21-23)$, yet we have discovered that certain anti- $\gamma \delta \mathrm{TCR}$ antibodies cause $\gamma \delta \mathrm{Tc}$ apoptosis. This mechanism may be Fas dependent, suggested by the uncoupling of TCR signaling and apoptosis revealed by anti-CD3 stimulation of mature conventional T cells in wild type (B6) versus Fas-deficient (B6.lpr) mice (Fas-deficient T cells did not undergo apoptosis) (29).

Gan and colleagues also described Fas-dependent apoptosis of Daudi activated but not naïve human $\gamma \delta$ Tc stimulated with 5A6.E9 in the context of magnetic cell separation (30). While Fas was present throughout, surface expression of FasL on restimulated cells was most pronounced at $8 \mathrm{~h}$ poststimulation, suggesting that an incubation time of $4 \mathrm{~h}$ for a cytotoxicity assay is appropriate to avoid even more pronounced effector cell death (30). Our kinetics experiment with B1-treated $\gamma \delta \mathrm{Tc}$ showed that appreciable cell death was first detectable between 3.5 and $4.5 \mathrm{~h}$ (Figure S5 in Supplementary Material), supporting even shorter incubation times. In line with most of our results with 5A6.E9 (Figures 2A-D,F), the presence or absence of IL-2 in culture after stimulation did not alter the rate or extent of $\gamma \delta$ Tc cell death (30).

We typically include exogenous IL-2 in our cytotoxicity assays (Figure 1), since IL-2 is thought to enhance the cytotoxic potential of $\gamma \delta \mathrm{Tc}$. While not inducing cytotoxicity on its own, IL-2 increased V $\delta 2 \gamma \delta$ Tc lysis of Daudi Burkitt's lymphoma and TU167 squamous carcinoma cell lines in a dose-dependent manner in the presence of tumor cells or phosphoantigen (31). Janssen and colleagues determined that the apoptotic effect of TCR stimulation was IL-2 dependent (24); such synergy was also evident in $\gamma \delta \mathrm{Tc}$ treated with the $\mathrm{B} 1$ anti- $\gamma \delta \mathrm{TCR}$ clone in the presence of IL-2 (Figure 2). In published reports of in vitro $\gamma \delta \mathrm{Tc}$ 


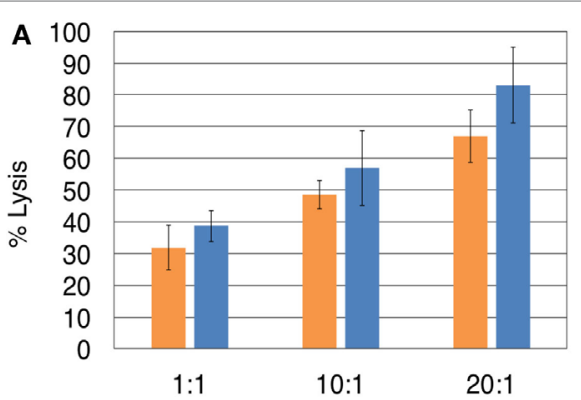

C

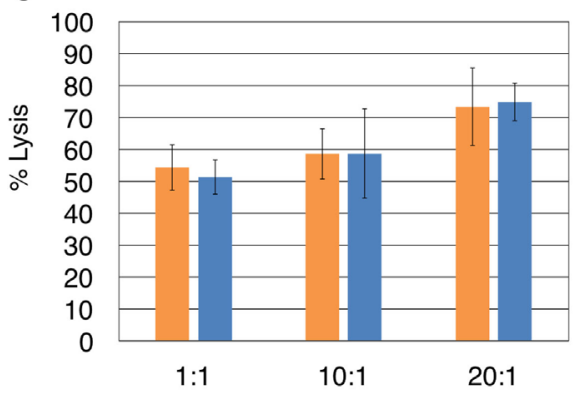

E

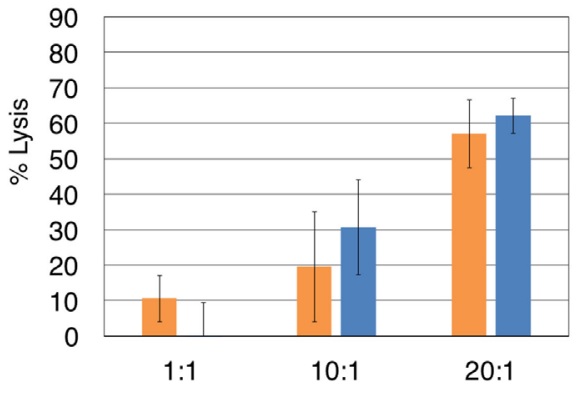

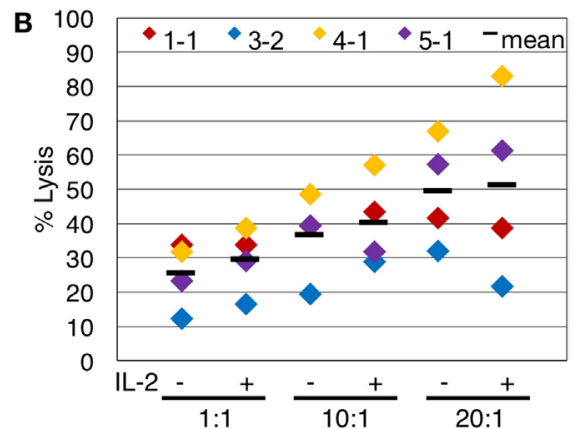

D

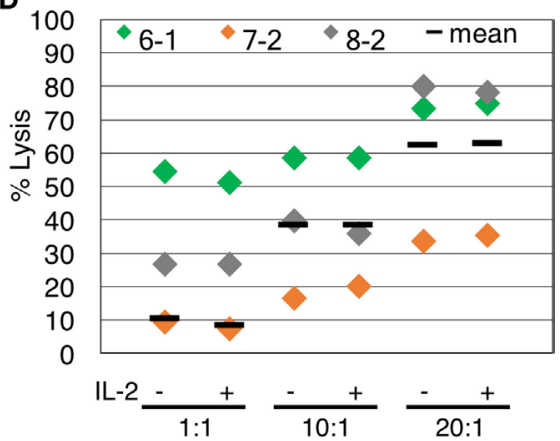

F

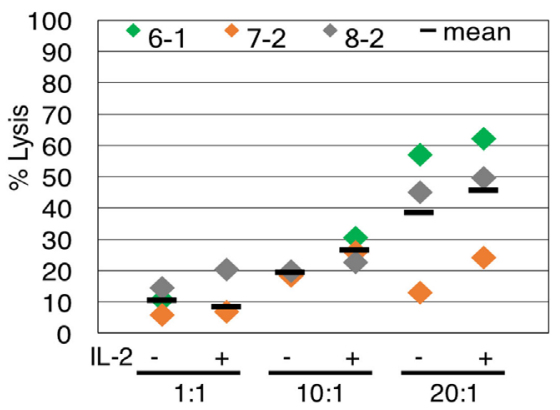

FIGURE 3 | The presence of interleukin-2 (IL-2) does not significantly impact $\gamma \delta$ Tc cytotoxicity against breast cancer cell lines. Comparison of $\gamma \delta ~ T$ cell cytotoxicity, at the indicated effector:target ratios, in the absence (orange) or presence (blue) of IL-2, against (A) T47D (Donor 4, culture 1, day $21 \gamma \delta \mathrm{T}$ cells), representative of four independent experiments. (B) Compiled results of four independent cytotoxicity experiments using T47D cells as targets. (C) MCF-7 (Donor 6 day $19 \gamma \delta T$ cells), representative of three independent experiments. (D) Compiled results of three independent cytotoxicity experiments using MCF-7 cells as targets. (E) MDA-MB-231 breast cancer cell targets (Donor 6 day $19 \gamma \delta$ T cells). (F) Compiled results of three independent cytotoxicity experiments using MDA-MB-231 cells as targets. Two-way ANOVA followed by Bonferroni's multiple comparisons analysis were performed for all experiments; no significant differences were revealed.

cytotoxicity against breast cancer cell lines, it is unclear whether IL-2 was included in the assays $(20,32)$. Our data suggest that exogenous IL-2 is unnecessary for the assessment of $\gamma \delta$ Tc cytotoxicity against breast cancer cell lines (Figure 3) and indeed its propensity to drive activated T cells into apoptosis (33) further warrants its exclusion from such assays.

Our experiments have revealed that the 5A6.E9 clone is a better mAb to "block" the $\gamma \delta T C R$ than B1, as it typically induced the least amount of apoptosis and appeared not to synergize with IL-2 to enhance this unwanted effect; however, this behavior was somewhat donor- and likely $\gamma \delta \mathrm{Tc}$ subset dependent (Figures 2A-D,F), further discussed below.

We admittedly did not screen every available anti- $\gamma \delta T C R$ antibody in our assays, but rather sought to document this unwanted effect to encourage investigators to consider this issue when performing their own blocking experiments. It is possible that primary $\gamma \delta$ Tc generated using other protocols may be more or less sensitive to apoptosis induction via $\mathrm{B} 1$ or $11 \mathrm{~F} 2$. Thus, it will be important for researchers to test blocking $\mathrm{mAb}$ on $\gamma \delta \mathrm{Tc}$ cultured using their own protocols. For example, Guo et al's apoptosisresistant $\gamma \delta \mathrm{Tc}(34)$ may be less susceptible to B1-induced apoptosis than $\gamma \delta$ Tc cultured in our lab (9). In a later study with these cells, it is unclear which anti- $\gamma \delta$ TCR clone was used for blocking (20); however, the best way to assess $\gamma \delta$ Tc susceptibility to apoptosis upon anti- $\gamma \delta$ TCR treatment would have been to perform blocking assays on $\gamma \delta$ Tc alone and assess viability in parallel with cytotoxicity assays, as we have done here (Figure 4).

We did not test V-segment-specific mAb in our study; however, Janssen and colleagues have shown that $\mathrm{V} \gamma$ 9-specific mAb $7 \mathrm{~A} 5$ induced apoptosis in $\gamma \delta \mathrm{Tc}$ clones, potentiated by addition of 

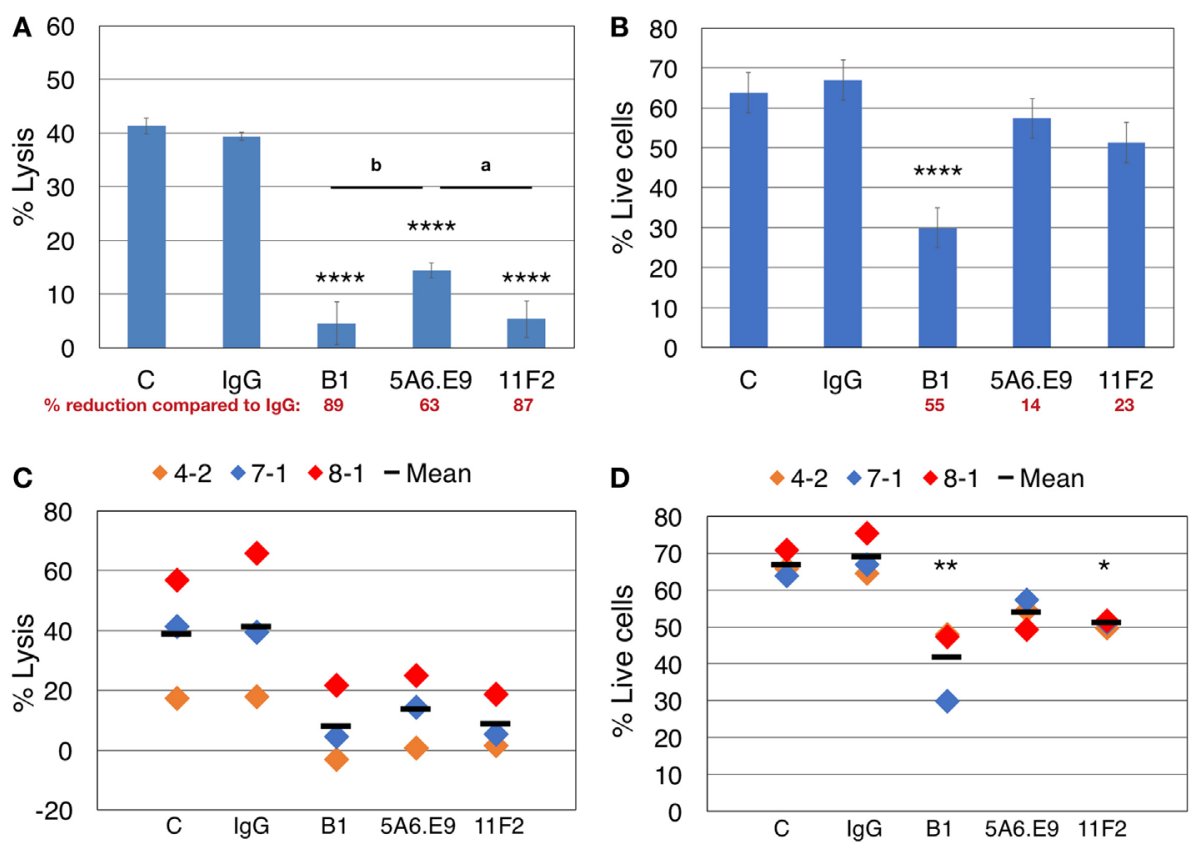

FIGURE 4 | Effector blocking alone and blocking cytotoxicity assays should be performed in parallel to account for apoptosis induced by anti- $\gamma \delta T C R$ antibodies. (A) Donor 7 day 19 primary human $\gamma \delta$ T cells were preincubated for 30 min with the indicated antibodies (1 $\mu \mathrm{g} /$ well) and then incubated with calcein AM-labeled targets in triplicate at a 20:1 effector:target (E:T) ratio for 4 h. (B) 600,000 Donor 7 day $19 \gamma \delta$ T cells were stimulated with $1 \mu \mathrm{g}$ of the indicated antibodies for $4.5 \mathrm{~h}$ and labeled with Zombie Aqua viability dye and annexin V (AnnV) FITC; shown are the \% live cells that excluded the uptake of dye and were negative for AnnV. (C) Compiled blocking and cytotoxicity results of three independent experiments. (D) Compiled blocking and viability results of three independent experiments. Panels (A,B) were done in parallel, as were experiments shown in panels (C,D). A significant reduction in \% lysis (A,C) or \% live cells (B,D) was determined by one-way ANOVA followed by Bonferroni's pairwise multiple comparison post hoc analysis $\left[{ }^{\star} P<0.05\right.$, ${ }^{\star \star} P<0.01$, ${ }^{\star \star \star \star} P<0.0001$ versus IgG; among antibody treatments (as indicated): a $P<0.05$; $\left.{ }^{\mathrm{b}} P<0.01\right]$. Percent reduction compared to $\operatorname{lgG}$ (in red font) was calculated: $100-(\%$ lysis or live cells treated with antibody/lgG $\times 100)$.

IL-2 (24). The extent of apoptosis was the same with soluble or immobilized $\mathrm{mAb}$, as we also observed with B1 (Figures 2H,I). It could be informative to determine whether other $\mathrm{V}$-segmentspecific $\mathrm{mAb}$ induce $\gamma \delta \mathrm{Tc}$ apoptosis; if researchers propose to employ these $\mathrm{mAb}$ in blocking experiments, then it would indeed be important to test for this effect in advance. If apoptosis induction is evident, these $\mathrm{mAb}$ may be employed for specific in vivo elimination of these cells. Furthermore, if we could map the epitopes recognized by pan- $\gamma \delta \mathrm{TCR}$ and $\mathrm{V}$-segment-specific $\mathrm{mAb}$ that induce apoptosis in $\gamma \delta \mathrm{Tc}$, perhaps small molecules could be designed to induce apoptotic signaling pathways and thereby deplete specific $\gamma \delta \mathrm{Tc}$ subsets implicated in various pathologies in vivo.

Controversy over the effectiveness of in vivo depletion strategies was addressed by Koenecke and colleagues, who determined that injection of anti- $\gamma \delta \mathrm{TCR} \mathrm{mAb}$ into mice did not delete $\gamma \delta \mathrm{Tc}$ as expected, but rather caused receptor internalization, rendering the cells "invisible" (35). Kinetics experiments revealed, however, that $\sim 10-20 \%$ of $\gamma \delta$ Tc were indeed lost as of 14 days; the authors attributed this to activation-induced $\gamma \delta \mathrm{Tc}$ death (35), which is what we observed here on a much shorter time scale in vitro. While GL3 and UC7-13D5 mAb recognize at least partially overlapping epitopes, the higher affinity of GL3 led to greater TCR internalization (35), confirming that even $\mathrm{mAb}$ recognizing similar structures have differential effects and should therefore be tested and chosen wisely.
In our hands, in separate experiments, $\mathrm{B} 1 \mathrm{mAb}$ stimulation typically resulted in an average $\gamma \delta$ Tc viability loss of $\sim 10-15 \%$ (Figures 1D and 2B-G). This was in line with cytotoxicity differences observed comparing blocking with B1 to 5A6.E9 $(38.6-24.8 \%=13.8 \%)$, suggesting that roughly half of the dramatic "blocking" effect observed upon B1 incubation can be attributed to unintended induction of apoptosis in $\gamma \delta \mathrm{Tc}$. While in assays done in parallel these numbers were higher (Figure 4), the estimate of a $\sim 50 \%$ reduction attributable to B1-induced cell death still held true. Importantly, our results with 5A6.E9 suggest that the $\gamma \delta$ TCR is indeed involved in $\gamma \delta$ Tc killing of breast cancer targets.

While we did not directly address the susceptibility of individual $\gamma \delta \mathrm{Tc}$ subsets to apoptosis induction via anti- $\gamma \delta \mathrm{TCR}$ antibodies, we might assume that the V $\delta 2$ subset was most strongly affected, due to this subset's documented sensitivity to activation-induced cell death (36-38). Donor culture 4-1 was mainly V82 (78.8\%, Figure S3A and Table S1 in Supplementary Material) and susceptible to enhanced apoptosis through IL-2 in combination with each of the three tested anti-TCR $\gamma \delta \mathrm{mAb}$ (Figures 2E-G; Figure S3B in Supplementary Material). Note that Student's $t$-tests were employed to assess significant differences in IL-2-treated versus -untreated cells in Figures 2E-G, but that ANOVA was used for the full experiment in Figure S3B in Supplementary Material, explaining differences in statistical outcomes for 11F2-treated samples (compare Figure 2G and Figure S3B in Supplementary 
Material). Cultures comprising lower percentages of V82 cells (1-2 and 3-2, Table S1 in Supplementary Material) exhibited little to no difference in viability upon incubation with 5A6.E9 or 11F2, with or without IL-2 (Figures 2F,G). These data suggest that V 22 is more sensitive to apoptosis induced by anti-TCR $\gamma \delta \mathrm{mAb}$ in the presence of IL-2. Since most studies focus on the V 22 subset, it is crucial that researchers take this unintended effect into account.

Previous blocking assays reported in the literature have potentially unwittingly overstated $\gamma \delta$ TCR involvement in lysis of target cells by assuming that decreased target death is due to blocking of the TCR, not realizing that a proportion of effector $\gamma \delta$ Tc may have undergone apoptosis. If, for example, anti-TCRV $1 \mathrm{mAb}$ clones induce $\gamma \delta \mathrm{Tc}$ apoptosis, then the TCR may not be involved in V $\delta 1$ $\gamma \delta \mathrm{Tc}$ killing of MEC1 leukemia cells since B1 and anti-V $\delta 1$ both appeared to "block" MEC1 lysis to a similar extent (14). In our own previous work, Immu510 and B1.1 clones decreased percent lysis of PC-3M prostate cancer cells to the same extent, suggesting that Immu510 may be as detrimental to $\gamma \delta$ Tc viability as B1.1 (9). In that experiment, using a V 2 2-predominant culture (77.4\%

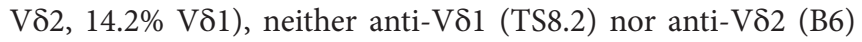
clones significantly reduced cytotoxicity against PC-3M, suggesting that the TCR was not involved (9). In another experiment with a V $\delta 1$ predominant $\gamma \delta \mathrm{Tc}$ culture $(55.1 \% \mathrm{~V} \delta 1,11.7 \% \mathrm{~V} \delta 2)$, derived from a different donor, anti-V $\delta 1$ did decrease lysis significantly, yet this may have been due to loss of $\gamma \delta T c$ as opposed

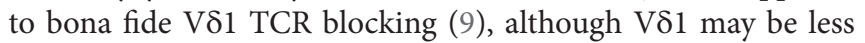
susceptible to apoptosis induction than V $\delta 2$, as discussed above. In contrast, a lack of decrease in tumor cell death after mAb treatment suggests that the $\gamma \delta \mathrm{Tc}$ employed were not susceptible to $\mathrm{mAb}$-induced apoptosis. For example, $\mathrm{V} \delta 1 \gamma \delta \mathrm{Tc}$ expressing natural cytotoxicity receptors were not susceptible to apoptosis induced by B1.1 or Immu510, as no drop in MOLT4 lysis was observed (10). Likewise, blocking with B1.1 and Immu510 had no influence on V $\delta 2 \gamma \delta \mathrm{Tc}$ cytotoxicity against Jurkat or Molt4 (18). Thus, the TCR was not implicated in cytotoxicity and no false misinterpretation resulted $(10,18)$. Yet $\gamma \delta$ TCR involvement in killing of ULBP4-overexpressing murine thymoma EL4 (22) as well as hMSH2-expressing HeLa cells (23) may have been overstated, if the $\gamma \delta$ Tc employed in these studies were as susceptible to B1.1-mediated apoptosis as ours were.

In conclusion, we strongly suggest that researchers employing the mAb blocking assay using anti- $\gamma \delta \mathrm{TCR}$ mAb perform $\gamma \delta \mathrm{Tc}$ alone controls in parallel, to quantify the extent of effector cell death occurring as a result of mAb treatment. This cell death can then be taken into account and subtracted from the difference observed in cytotoxicity upon application of this mAb, which should give a more accurate value for the extent to which true receptor blocking impairs cytotoxicity. IL-2 may be excluded from cytotoxicity assays to minimize the deadly synergy observed

\section{REFERENCES}

1. Vantourout P, Hayday A. Six-of-the-best: unique contributions of gammadelta T cells to immunology. Nat Rev Immunol (2013) 13:88-100. doi:10.1038/ nri3384

2. Silva-Santos B, Serre K, Norell H. gammadelta T cells in cancer. Nat Rev Immunol (2015) 15:683-91. doi:10.1038/nri3904 upon B1 stimulation, keeping in mind that this may reduce overall cytotoxicity and thus perhaps should be tested for each target cell line in advance. Previous work using B1 or B1.1 for blocking, ours included, should be reevaluated in this light. Perhaps the $\gamma \delta T C R$ is not as involved in target killing as we thought.

\section{ETHICS STATEMENT}

This study was carried out in accordance with the recommendations of the Research Ethics Guidelines, Health Research Ethics Board of Alberta-Cancer Committee with written informed consent from all subjects. All subjects gave written informed consent in accordance with the Declaration of Helsinki. The protocol was approved by the Health Research Ethics Board of Alberta-Cancer Committee.

\section{AUTHOR CONTRIBUTIONS}

All the authors contributed to research design. ID and GS conducted experiments and performed data analysis. GS wrote the manuscript.

\section{ACKNOWLEDGMENTS}

We would like to thank Dr. Dalam Ly for inspiring us to pursue this line of research by suggesting that the B1 mAb may cause $\gamma \delta$ Tc cell death. We also thank Dr. Rebecca O’Brien for her insights into in vivo depletion of $\gamma \delta \mathrm{Tc}$. This work has been supported by the Sawin-Baldwin Chair in Ovarian Cancer, Dr. Anthony Noujaim Legacy Oncology Chair and Alberta Innovates Health Solutions Translational Health Chair to LMP. We thank Dr. Aja Rieger (Flow Cytometry Core, Faculty of Medicine and Dentistry, University of Alberta) for her support. We also thank Dr. Ing Swie Goping for providing us with antibodies to cleaved Caspase 3.

\section{FUNDING}

This project has been funded by a Cancer Research Society Operating Grant (LMP and GS), Alberta Cancer Foundation Antoine Noujain and University of Alberta Doctoral Recruitment Scholarships (ID), and an Alberta Innovates Health Solutions Translational Health Chair (LMP).

\section{SUPPLEMENTARY MATERIAL}

The Supplementary Material for this article can be found online at http://journal.frontiersin.org/article/10.3389/fimmu.2017.00776/ full\#supplementary-material.

3. Siegers GM, Lamb LS Jr. Cytotoxic and regulatory properties of circulating Vdelta1+ gammadelta T cells: a new player on the cell therapy field? Mol Ther (2014) 22:1416-22. doi:10.1038/mt.2014.104

4. Dieli F, Vermijlen D, Fulfaro F, Caccamo N, Meraviglia S, Cicero G, et al. Targeting human \{gamma\}delta\} T cells with zoledronate and interleukin-2 for immunotherapy of hormone-refractory prostate cancer. Cancer Res (2007) 67:7450-7. doi:10.1158/0008-5472.CAN-07-0199 
5. Lang JM, Kaikobad MR, Wallace M, Staab MJ, Horvath DL, Wilding G, et al. Pilot trial of interleukin-2 and zoledronic acid to augment gammadelta $\mathrm{T}$ cells as treatment for patients with refractory renal cell carcinoma. Cancer Immunol Immunother (2011) 60:1447-60. doi:10.1007/s00262-011-1049-8

6. Meraviglia S, Eberl M, Vermijlen D, Todaro M, Buccheri S, Cicero G, et al. In vivo manipulation of Vgamma9Vdelta2 $\mathrm{T}$ cells with zoledronate and lowdose interleukin-2 for immunotherapy of advanced breast cancer patients. Clin Exp Immunol (2010) 161:290-7. doi:10.1111/j.1365-2249.2010.04167.x

7. Wilhelm M, Kunzmann V, Eckstein S, Reimer P, Weissinger F, Ruediger T, et al. Gammadelta $\mathrm{T}$ cells for immune therapy of patients with lymphoid malignancies. Blood (2003) 102:200-6. doi:10.1182/blood-2002-12-3665

8. Fisher JP, Heuijerjans J, Yan M, Gustafsson K, Anderson J. Gammadelta $\mathrm{T}$ cells for cancer immunotherapy: a systematic review of clinical trials. Oncoimmunology (2014) 3:e27572. doi:10.4161/onci.27572

9. Siegers GM, Ribot EJ, Keating A, Foster PJ. Extensive expansion of primary human gamma delta $\mathrm{T}$ cells generates cytotoxic effector memory cells that can be labeled with Feraheme for cellular MRI. Cancer Immunol Immunother (2013) 62:571-83. doi:10.1007/s00262-012-1353-y

10. Correia DV, Fogli M, Hudspeth K, da Silva MG, Mavilio D, Silva-Santos B. Differentiation of human peripheral blood Vdeltal+ $\mathrm{T}$ cells expressing the natural cytotoxicity receptor NKp30 for recognition of lymphoid leukemia cells. Blood (2011) 118:992-1001. doi:10.1182/blood-2011-02-339135

11. von Lilienfeld-Toal M, Nattermann J, Feldmann G, Sievers E, Frank S, Strehl J, et al. Activated gammadelta $\mathrm{T}$ cells express the natural cytotoxicity receptor natural killer p 44 and show cytotoxic activity against myeloma cells. Clin Exp Immunol (2006) 144:528-33. doi:10.1111/j.1365-2249.2006.03078.x

12. Rivas A, Koide J, Cleary ML, Engleman EG. Evidence for involvement of the gamma, delta $\mathrm{T}$ cell antigen receptor in cytotoxicity mediated by human alloantigen-specific T cell clones. J Immunol (1989) 142:1840-6.

13. Liu Z, Guo BL, Gehrs BC, Nan L, Lopez RD. Ex vivo expanded human Vgamma9Vdelta2+ gammadelta-T cells mediate innate antitumor activity against human prostate cancer cells in vitro. J Urol (2005) 173:1552-6. doi:10.1097/01.ju.0000154355.45816.0b

14. Almeida AR, Correia DV, Fernandes-Platzgummer A, da Silva CL, da Silva MG, Anjos DR, et al. Delta one T cells for immunotherapy of chronic lymphocytic leukemia: clinical-grade expansion/differentiation and preclinical proof of concept. Clin Cancer Res (2016) 22:5795-804. doi:10.1158/10780432.CCR-16-0597

15. Chitadze G, Lettau M, Luecke S, Wang T, Janssen O, Fürst D, et al. NKG2Dand T-cell receptor-dependent lysis of malignant glioma cell lines by human gammadelta $\mathrm{T}$ cells: modulation by temozolomide and A disintegrin and metalloproteases 10 and 17 inhibitors. Oncoimmunology (2015) 5(4):e1093276. doi:10.1080/2162402X.2015.1093276

16. Wrobel P, Shojaei H, Schittek B, Gieseler F, Wollenberg B, Kalthoff H, et al. Lysis of a broad range of epithelial tumour cells by human gamma delta T cells: involvement of NKG2D ligands and T-cell receptor- versus NKG2D-dependent recognition. Scand J Immunol (2007) 66:320-8. doi:10.1111/j.1365-3083.2007.01963.x

17. Fisch P, Malkovsky M, Braakman E, Sturm E, Bolhuis RL, Prieve A, et al. Gamma/delta $\mathrm{T}$ cell clones and natural killer cell clones mediate distinct patterns of non-major histocompatibility complex-restricted cytolysis. J Exp Med (1990) 171:1567-79. doi:10.1084/jem.171.5.1567

18. Lança T, Correia DV, Moita CF, Raquel H, Neves-Costa A, Ferreira C, et al. The MHC class Ib protein ULBP1 is a nonredundant determinant of leukemia/lymphoma susceptibility to gammadelta T-cell cytotoxicity. Blood (2010) 115:2407-11. doi:10.1182/blood-2009-08-237123

19. Deniger DC, Maiti SN, Mi T, Switzer KC, Ramachandran V, Hurton LV, et al. Activating and propagating polyclonal gamma delta $\mathrm{T}$ cells with broad specificity for malignancies. Clin Cancer Res (2014) 20:5708-19. doi:10.1158/10780432.CCR-13-3451

20. Guo BL, Liu Z, Aldrich WA, Lopez RD. Innate anti-breast cancer immunity of apoptosis-resistant human gammadelta-T cells. Breast Cancer Res Treat (2005) 93:169-75. doi:10.1007/s10549-005-4792-8

21. Maeurer MJ, Martin D, Walter W, Liu K, Zitvogel L, Halusczcak K, et al. Human intestinal Vdelta1+ lymphocytes recognize tumor cells of epithelial origin. J Exp Med (1996) 183:1681-96. doi:10.1084/jem.183.4.1681

22. Kong Y, Cao W, Xi X, Ma C, Cui L, He W. The NKG2D ligand ULBP4 binds to TCRgamma9/delta2 and induces cytotoxicity to tumor cells through both TCRgammadelta and NKG2D. Blood (2009) 114:310-7. doi:10.1182/ blood-2008-12-196287
23. Dai Y, Chen H, Mo C, Cui L, He W. Ectopically expressed human tumor biomarker MutS homologue 2 is a novel endogenous ligand that is recognized by human gammadelta $\mathrm{T}$ cells to induce innate anti-tumor/ virus immunity. J Biol Chem (2012) 287:16812-9. doi:10.1074/jbc. M111.327650

24. Janssen O, Wesselborg S, Heckl-Ostreicher B, Pechhold K, Bender A, Schondelmaier $\mathrm{S}$, et al. $\mathrm{T}$ cell receptor/CD3-signaling induces death by apoptosis in human $\mathrm{T}$ cell receptor gamma delta $+\mathrm{T}$ cells. J Immunol (1991) 146:35-9.

25. Fotedar A, Boyer M, Smart W, Widtman J, Fraga E, Singh B. Fine specificity of antigen recognition by $\mathrm{T}$ cell hybridoma clones specific for poly-18: a synthetic polypeptide antigen of defined sequence and conformation. J Immunol (1985) 135:3028-33.

26. Band H, Hochstenbach F, McLean J, Hata S, Krangel MS, Brenner MB. Immunochemical proof that a novel rearranging gene encodes the $\mathrm{T}$ cell receptor delta subunit. Science (1987) 238:682-4. doi:10.1126/science. 3672118

27. Borst J, van Dongen JJ, Bolhuis RL, Peters PJ, Hafler DA, de Vries E, et al. Distinct molecular forms of human $\mathrm{T}$ cell receptor gamma/delta detected on viable T cells by a monoclonal antibody. J Exp Med (1988) 167:1625-44. doi:10.1084/jem.167.5.1625

28. Koopman G, Reutelingsperger CP, Kuijten GA, Keehnen RM, Pals ST, van Oers $\mathrm{MH}$. Annexin $\mathrm{V}$ for flow cytometric detection of phosphatidylserine expression on B cells undergoing apoptosis. Blood (1994) 84:1415-20.

29. Russell JH, Rush B, Weaver C, Wang R. Mature T cells of autoimmune lpr/ lpr mice have a defect in antigen-stimulated suicide. Proc Natl Acad Sci U S A (1993) 90:4409-13. doi:10.1073/pnas.90.10.4409

30. Gan YH, Lui SS, Malkovsky M. Differential susceptibility of naive and activated human gammadelta $\mathrm{T}$ cells to activation-induced cell death by T-cell receptor cross-linking. Mol Med (2001) 7:636-43.

31. Li H, David Pauza C. Interplay of T-cell receptor and interleukin-2 signalling in Vgamma2Vdelta2 T-cell cytotoxicity. Immunology (2010) 132:96-103. doi:10.1111/j.1365-2567.2010.03343.x

32. Gaafar A, Aljurf MD, Al-Sulaiman A, Iqniebi A, Manogaran PS, Mohamed GE, et al. Defective gammadelta T-cell function and granzyme B gene polymorphism in a cohort of newly diagnosed breast cancer patients. Exp Hematol (2009) 37:838-48. doi:10.1016/j.exphem.2009.04.003

33. Lenardo MJ. Interleukin-2 programs mouse alpha beta $\mathrm{T}$ lymphocytes for apoptosis. Nature (1991) 353:858-61. doi:10.1038/353858a0

34. Lopez RD, Xu S, Guo B, Negrin RS, Waller EK. CD2-mediated IL-12-dependent signals render human gamma delta- $\mathrm{T}$ cells resistant to mitogen-induced apoptosis, permitting the large-scale ex vivo expansion of functionally distinct lymphocytes: implications for the development of adoptive immunotherapy strategies. Blood (2000) 96(12):3828-37.

35. Koenecke C, Chennupati V, Schmitz S, Malissen B, Förster R, Prinz I. In vivo application of $\mathrm{mAb}$ directed against the gammadelta TCR does not deplete but generates "invisible" gammadelta T cells. Eur J Immunol (2009) 39:372-9. doi:10.1002/eji.200838741

36. Bryant NL, Suarez-Cuervo C, Gillespie GY, Markert JM, Nabors LB, Meleth S, et al. Characterization and immunotherapeutic potential of $\gamma \delta$ T cells in patients with glioblastoma. Neuro Oncol (2009) 11(4):357-67. doi:10.1215/15228517-2008-111

37. Argentati K, Re F, Serresi S, Tucci MG, Bartozzi B, Bernardini G, et al. Reduced number and impaired function of circulating gamma delta $\mathrm{T}$ cells in patients with cutaneous primary melanoma. J Invest Dermatol (2003) 120:829-34. doi:10.1046/j.1523-1747.2003.12141.x

38. Kabelitz D, Pechhold K, Bender A, Wesselborg S, Wesch D, Friese K, et al. Activation and activation-driven death of human gamma/delta $\mathrm{T}$ cells. Immunol Rev (1991) 120:71-88. doi:10.1111/j.1600-065X.1991.tb00588.x

Conflict of Interest Statement: The authors declare that the research was conducted in the absence of any commercial or financial relationships that could be construed as a potential conflict of interest.

Copyright $\odot 2017$ Dutta, Postovit and Siegers. This is an open-access article distributed under the terms of the Creative Commons Attribution License (CC BY). The use, distribution or reproduction in other forums is permitted, provided the original author(s) or licensor are credited and that the original publication in this journal is cited, in accordance with accepted academic practice. No use, distribution or reproduction is permitted which does not comply with these terms. 